\title{
BAKAT, MOTIVASI, HAMBATAN DAN HARAPAN MAHASISWA MENJADI ENTREPRENEUR
}

\author{
Jonbi $^{1}$, Jeanne Nadia Ingrida ${ }^{2}$, A.R. Indra Tjahjani ${ }^{3}$ and Wita Meutia ${ }^{4}$ \\ ${ }^{1}$ Jurusan Teknik Sipil, Universitas pancasila \\ Email:nanojbg@gmail.com \\ ${ }^{2}$ Peneliti, PT. John Idetama Teknik \\ Email: jeannenadia@icloud.com \\ ${ }^{3}$ Program Studi Teknik Sipil, Universitas Pancasila \\ Email:pong_58@Yahoo.com \\ ${ }^{3}$ Program Studi Teknik Sipil, Universitas Pancasila \\ Email: wita.meutia@univpancasila.ac.id
}

\begin{abstract}
The high growth of entrepreneurs is one way to deal with globalization, so the government is very serious in developing entrepreneurship programs, especially among students. But being an entrepreneur is not easy, due to several factors such as talent, motivation, obstacles and expectations. The purpose of this study was to determine the talents, motivations, barriers and expectations of students to become an entrepreneur. The respondents of this study were civil engineering students from the 2014-2021 class, totaling 275 students consisting of 180 men and 95 women. Then respondents were asked to answer a questionnaire consisting of 5 main questions related to entrepreneurial knowledge and future expectations. The results showed that the entrepreneurial talent among male students was higher with a percentage of $65.3 \%$ while female students were $56.8 \%$. Making a lot of money is the main motivation to become an entrepreneur, while the lack of capital as much as $55.8 \%$ is the main obstacle. The choice of business field to become an entrepreneur is not in accordance with the education taken by 53.6\%. Shortterm expectations are not appropriate by 54.5\%, while long-term expectations are in accordance with the percentage of $55.7 \%$.
\end{abstract}

Keywords: entrepreneurs; talent, motivation; barrier; hope

Pertumbuhnya entrepreneur yang tinggi merupakan salah satu cara untuk menghadapi Globalisasi, sehingga pemerintah sangat serius dalam mengembangkan program entrepreneurship khususnya dikalangan mahasiswa. Namun menjadi seorang entrepreneur tidaklah mudah, karena beberapa faktor seperti bakat, motivasi, hambatan dan harapan. Tujuan dari penelitian ini adalah untuk mengetahui bakat, motivasi, hambatan dan harapan mahasiswa untuk menjadi seorang entrepreneur. Responden penelitian ini adalah mahasiswa teknik sipil angkatan 2014-2021 yang berjumlah 275 mahasiswa terdiri dari 180 pria dan 95 wanita. Kemudian responden diminta untuk menjawab kuesioner yang terdiri dari 5 pertanyaan utama terkait pengetahuan entrepreneur dan harapan masa depan. Hasil penelitian menunjukkan bahwa bakat entrepreneur di kalangan mahasiswa pria lebih tinggi dengan persentase $65,3 \%$ sedangkan mahasiswi wanita sebesar 56,8\%. Menghasilkan banyak uang merupakan motivasi utama menjadi entrepreneur, sedangkan tidak ada modal sesesar 55,8\% merupakan hambatan utama. Pilihan bidang usaha menjadi entrepreneur tidak sesuai dengan pendidikan yang ditempuh sebesar 53,6\%. Harapan jangka pendek tidak sesuai sebesar 54,5\%, sedangkan jangka panjang sesuai dengan persentase sebesar 55,7\%.

Kata Kunci: entrepreneur; bakat, motivasi; hambatan; harapan.

\section{PENDAHULUAN}

\section{Latar Belakang}

Entrepreneur dalam beberapa tahun ini, diyakini menjadi suatu harapan dan driven bagi kemajuan ekonomi suatu negara. Kemakmuran sebuah negara, jika sedikitnya 2\% penduduknya menjadi entrepreneur (David Mc.Cleland, 2011), sedangkan Indonesia diperkirakan baru memiliki $0,18 \%$

Pertumbuhan bisnis entrepreneur akan lebih cepat karena memiliki sumber daya dan manajemen yang lebih efektif dibandingkan dengan manajemen konvensional (Bruck et al 2011). Institusi perguruan tinggi berupaya mengikuti tren yang muncul dimasyarakat dan 
menawarkan pengetahuan tentang entrepreneur secara formal (Labib Arafeh 2016). Program pelatihan dan kursus menjadi langkah penting untuk menumbuhkan komunitas entrepreneur yang mandiri, sehingga dapat menciptakan lapangan kerja dan dapat meningkatkan perekonomian negara. Perilaku calon entrepreneur mencari informasi, akses terhadap kredit, partisipasi dalam seminar/lokakarya tentang manajemen, merupakan proses yang sangat penting bagi seseorang jika ingin menjadi entrepreneur (Temidayo Gabriel Apata 2015). Oleh karenanya diperlukan tim entrepreneur, yang fokus untuk mengidentifikasi peluang bisnis dan memobilisasi sumber daya eksternal. Selain itu ada faktor eksternal lain seperti ekonomi dan lingkungan politik yang dapat mendorong atau menghambat peluang menjadi entrepreneur (Ahlem Omri dan Younes Boujelbene 2015). Dikalangan masyarakat masih ada pendapat bahwa untuk menjadi seorang entrepreneur hanya cocok untuk kalangan etnis tertentu saja dengan alasan merasa tidak memiliki bakat. Meskipun kebanyakan orang memiliki bakat dan kekuatan untuk menjadi seorang entreprenuer, tidak semua orang menyadari dan termotivasi untuk mewujudkanya. Penelitian ini merupakan salah satu upaya untuk lebih memahami bakat, motivasi, hambatan dan harapan dikalangan mahasiswa sebagai generasi penerus bangsa untuk menjadi entrepreuner.

Benefit dari penelitian ini dapat mengetahui potensi mahasiswa menjadi entrepreneur dan hubungan harapan terhadap masa depan mahasiswa terhadap jurusan yang ditekuninya.

\section{METODE PENELITIAN}

Responden penelitian ini adalah mahasiswa dan mahasiswi Teknik sipil dengan periode selama perkuliah tahun 2014-2021 berjumlah 275 yang terdiri dari 180 pria dan 95 wanita. Responden diminta memberikan jawaban atas pertanyaan sebagai berikut:

a. Mengukur potensi diri terhadap bakat menjadi entrepreneur dengan menjawab 14 pertanyaan

(David E. Rye, 1996) yang dimodifikasi interprestasinya yakni dengan jawaban ya atau tidak sebagai berikut :

Tabel 1. Intreprestasi bakat menjadi entrepreneur

\begin{tabular}{cccc}
\hline Kode & & Jawaban & Bakat \\
\hline & Ya & Tidak & \\
\hline A & $13-14$ & $1-0$ & Sangat bakat \\
\hline B & $11-12$ & $3-2$ & bakat \\
\hline C & $9-10$ & $5-4$ & Kurang berbakat \\
\hline D & $\leq 8$ & $\geq 6$ & Tidak berbakat \\
\hline
\end{tabular}

b. Faktor utama yang menjadi pendorong jika anda ingin menjadi seorang entrepreneur (pilih 3 (tiga) jawaban teratas:

1. Menggunakan keterampilan saya

2. Memperoleh Kontrol atas saya

3. Membangun keluarga

4. Menyukai tantangan

5. Hidup sebagaimana yang saya mau

6. Mendapatkan penghormatan/penghargaan

7. Menghasilkan banyak uang

8. Mewujudkan harapan orang lain

9. Alternatif terbaik yang ada

c. Hambatan utama jika anda ingin menjadi entrepreneur dengan memilih 1 jawaban. 
1. Tidak ada modal

2. Belum ada ide bisnis apa yang akan dijalankan

3. Tidak berminat

4. Alasan lain

d. Bidang usaha apa yang anda pilih jika anda menjadi entrepreneur.

e. Jelaskan apa harapan /mimpi anda tahun dan 10 tahun yang akan datang

\section{HASIL DAN PEMBAHASAN}

\section{Bakat}

Pada Gambar 1. menunjukkan bahwa mahasiswa pria lebih memiliki bakat menjadi entrepreneur sebesar $65,3 \%(\mathrm{~A}+\mathrm{B})$ dibandingkan dengan mahasiswi putri sebesar 56,8\% (A+B) Hasil ini sejalan dengan penelitian yang menyatakan perlu konsepsi dan informasi detail tentang pentingnya kekuatan pribadi untuk menjadi entrepreneur (eva et al, 2018). Sedangkan untuk pilihan D ( tidak berbakat), Mahasiswa wanita lebih tinggi sebesar 13,5\% dibandingkan pria hanya $6,9 \%$, hal ini dapat dijelaskan bahwa selama ini peran pria di Indonesia lebih besar dibandingkan dengan wanita.

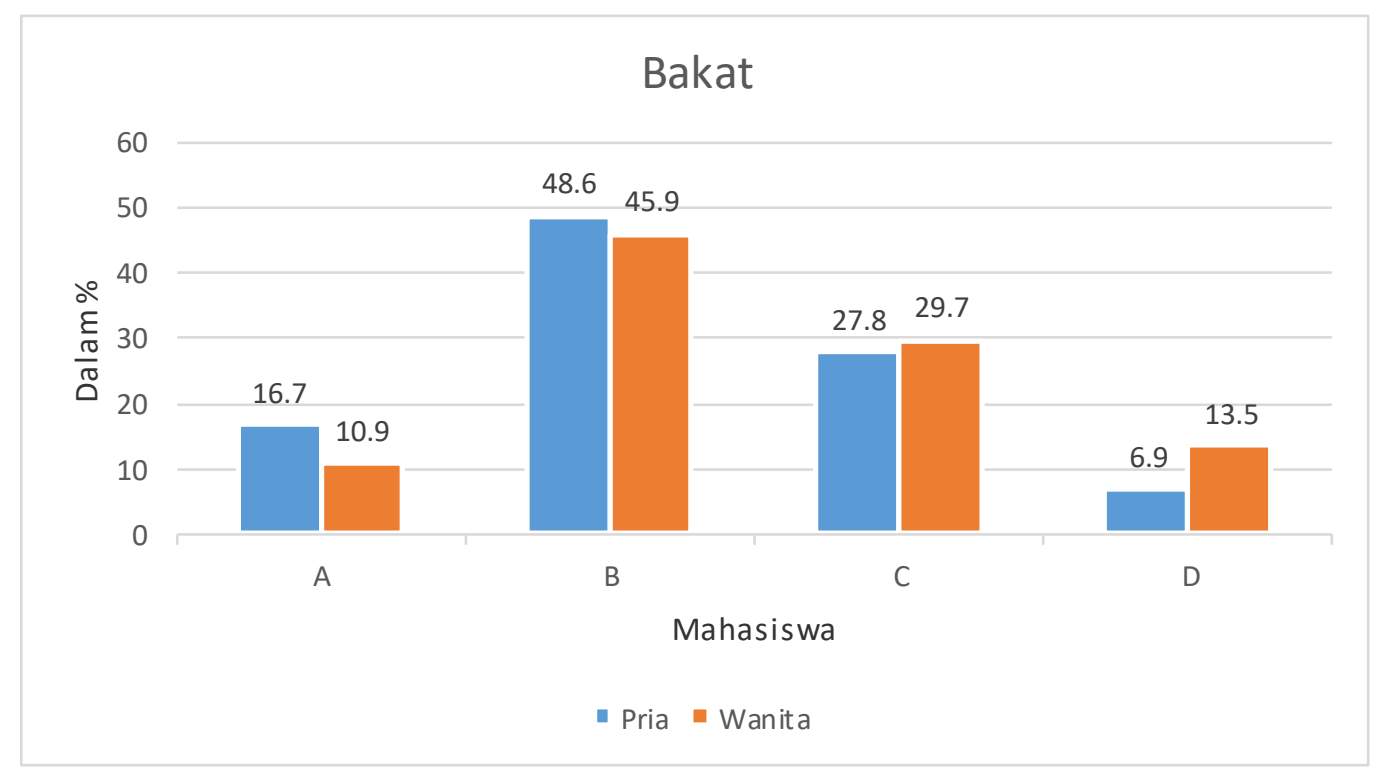

Gambar 1 Bakat mahasiswa menjadi entrepreneur

\section{Motivasi}

Motivasi menjadi entrepreneur dikalangan mahasiswa pada Gambar 2, memperlihatkan tiga motivasi utama yakni menghasilkan banyak uang merupakan menjadi motivasi utama dengan persentase sebesar 21,4\%, menggunakan keterampilan saya sebesar $20 \%$ dan hidup sebagai yang saya mau sebesar $12,4 \%$. Sedangkan di negara maju yang menjadi motivasi utama menjadi entrepreneur adalah menggunakan keterampilan saya sebesar 58\%, kemudian menghasilkan banyak uang hanya sebesar $16 \%$ dan menggunakan keterampilan saya sebesar $16 \%$. Untuk menjadi seorang entrepreneur ternyata niat/ minat tidak cukup, namun yang lebih penting implementasinya (Anne-Flore Adam dan Alain Fayolle 2016) 


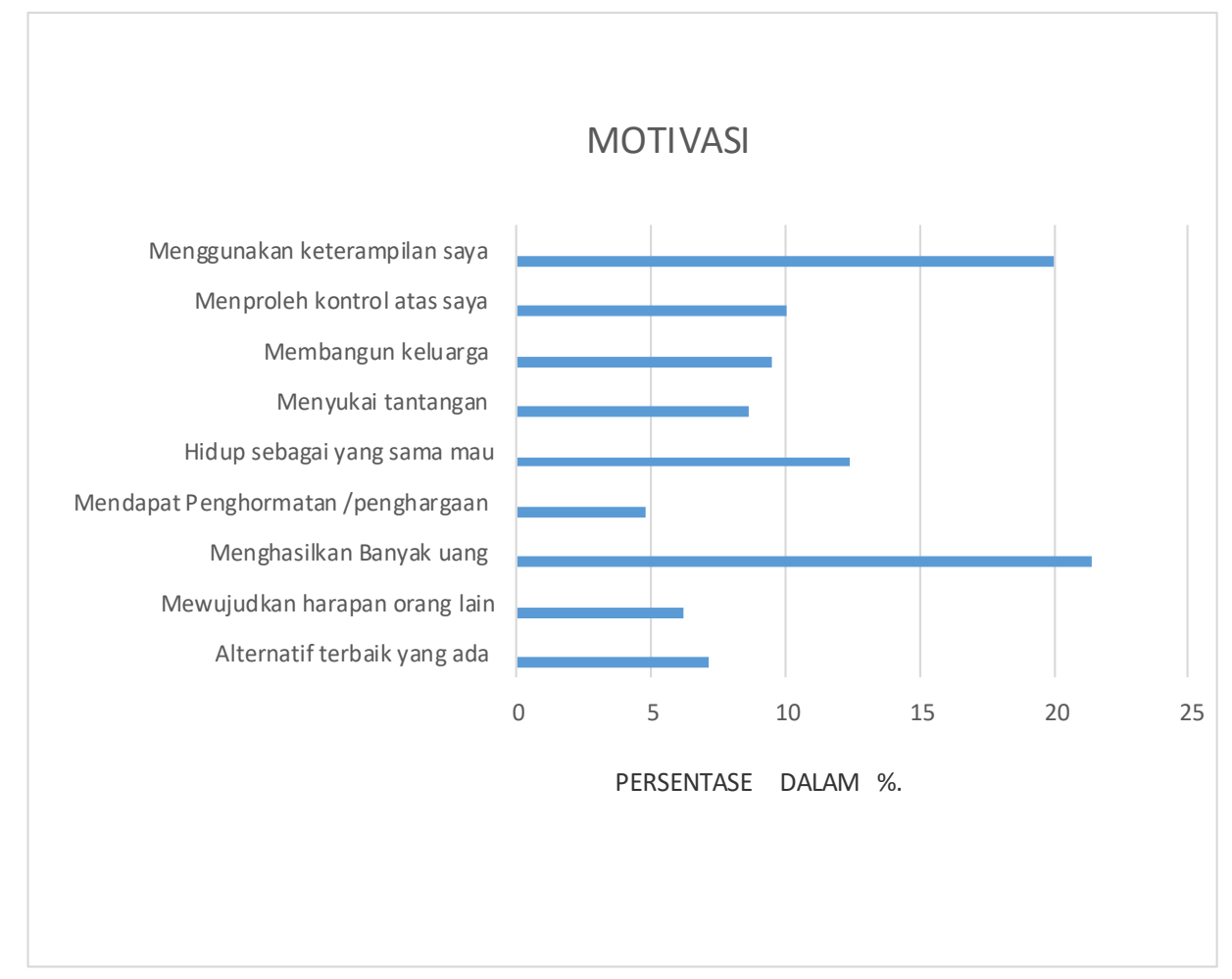

Gambar 2. Motivasi Mahasiswa menjadi entrepreneur

\section{Hambatan}

Hambatan mahasiswa menjadi entrepreneur ( Gambar 3) adalah tidak ada modal dengan persentase $55,8 \%$, belum ada ide bisnis $25 \%$, tidak berminat $1,6 \%$ dan alasan lain sebesar 17,6 $\%$.

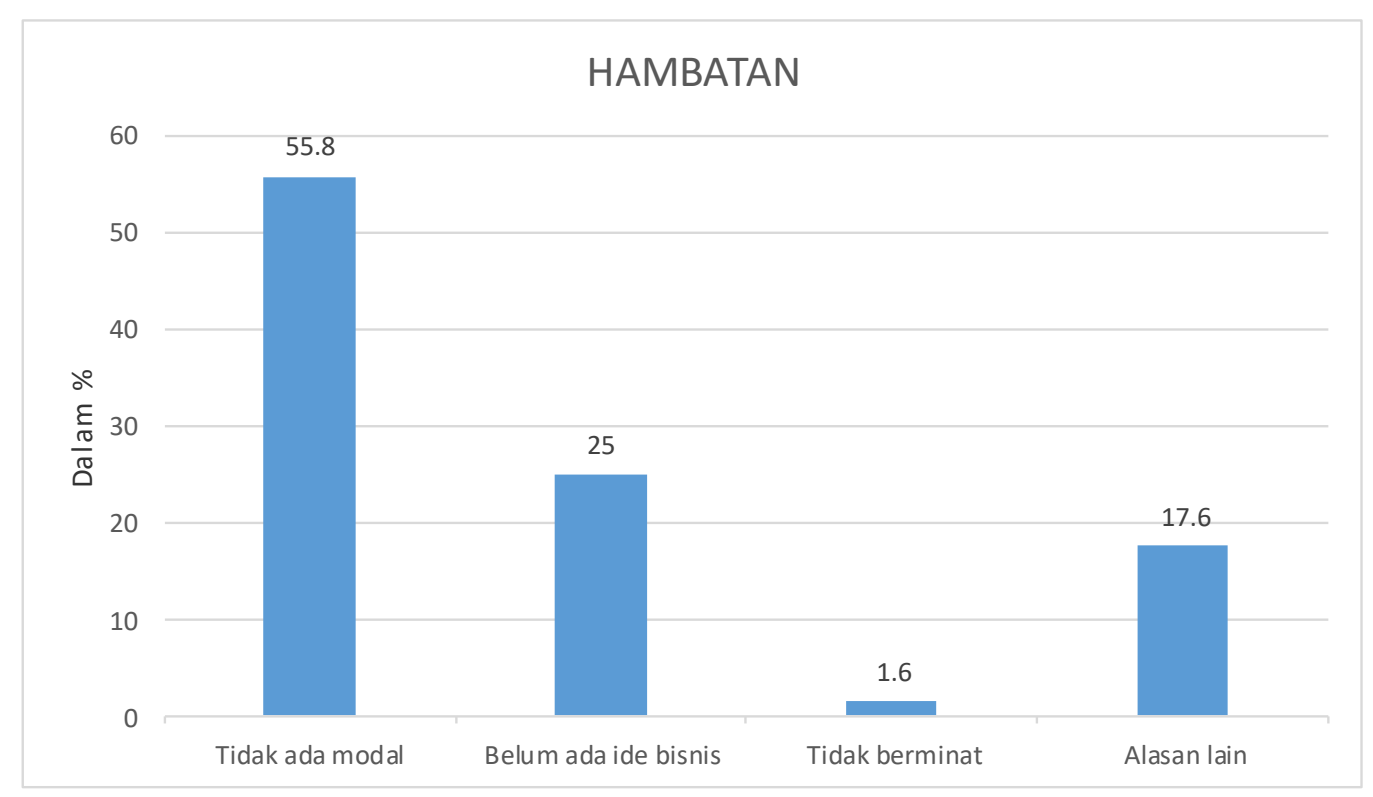

Gambar 3. Tantangan mahasiswa menjadi entrepreneur 
Hasil ini memperlihatkan demikian besarnya persoalan tidak ada modal, menjadi hambatan dikalangan mahasiswa untuk menjadi entrepreneur. Sedangkan menurut beberapa peneliti bahwa sebenarnya untuk menjadi entrepreneur tidak ada modal bukan menjadi hambatan utama ( Oleh karenanya sangat diperlukan informasi ini agar terjadi perubahan pola pikir, bahwa modal (uang ) seharusnya tidak menjadi hambatan untuk seseoarang ingin menjadi entrepreneur. Satu hal yang penting juga perlu dipahami bahwa keberhasilan seorang entrprenuer lebih pada hasil nyata dalam berkarya dibandingkan dengan formalitas (Muhammad et.al, 2020).

\section{Bidang Usaha}

Bidang usaha yang menjadi pilihan dikaitkan dengan jurusan teknik sipil (Gambar 4) terlihat bahwa bidang usaha yang dipilih, ternyata tidak sesuai sebesar 53,6\% dan yang sesuai $46,4 \%$.

Sesuai artinya bidang usaha yang dipilih masih ada hubungan dengan perkuliahan di jurusan teknik sipil, jika sebaliknya maka dikategorikan tidak sesuai.

Hasil ini menunjukkan bahwa masih kurang pengetahuan di kalangan mahasiswa akan pilihan jurusan teknik sipil terhadap langkah masa depannya. Hal ini berakibat banyak waktu terbuang dan biaya bagi mahasiswa dalam menghadapi masa depan.

Banyak entrepreneur muda menjalankan bisnis berbasis teknologi, dengan mayakini bahwa bisnis dalam bidang teknologi memiliki prospek yang tinggi (Thea van der Westhuizen dan Marialauda Joel Goyayi, 2020).

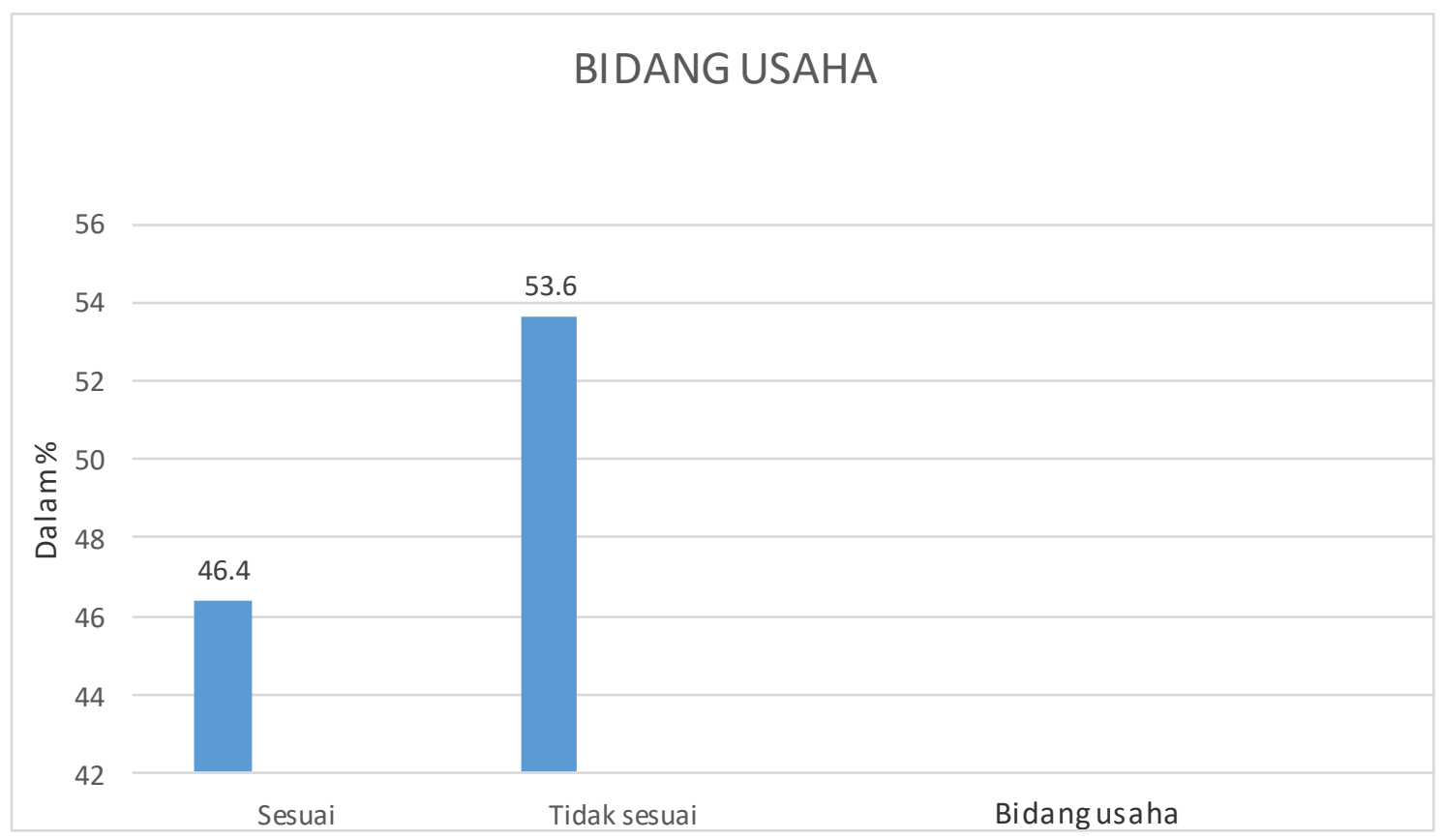

Gambar 4. Bidang usaha yang dipilih mahasiswa

\section{Harapan}

Harapan mahasiswa jangka pendek dan jangka panjang dapat dilihat pada Gambar 5. Pada jangka pendek ( 5 ) tahun ke depan ternyata harapan mahasiswa tidak sesuai dengan jurusan teknik sipil yang ditempuh di Univesitas Pancasila sebesar 54,5\%. Implikasinya mahasiswa yang mengambil jurusan teknik sipil setelah lulus, akan lebih banyak berkarya di luar bidang yang ditekuni semasa kuliah. Hal ini tentu sangat disayangkan karena selain tidak dapat langsung mengaplikasikan ilmu pengetahuannya juga terkesan banyak waktu yang terbuang, dan 
terbatasnya alumni teknik sipil yang sesuai dengan bidangnya. Temuan yang menarik dari riset ini, ternyata untuk jangka panjang (10 ) tahun harapan mahasiswa akan berkarya sesuai dengan jurusan teknik sipil meningkat dengan persentase sebesar 55,7\%. Hal ini dapat dijelaskan sebagai berikut pada jangka pendek mahasiswa akan berkarya untuk mendapatkan dana sebagai modal, setelah itu akan memulai berkarya sesuai bidang jurusan teknik sipil. Namun langkah ini tidak tepat karena untuk menjadi entrepreneur handal masalah waktu dan berani memulai adalah faktor penting dalam berwirausaha. Untuk itu perlu di Perguruan tinggi mengembangan system pembelajaran agar tercipta entrepreneur berkelanjutan (petra et.al, 2018).

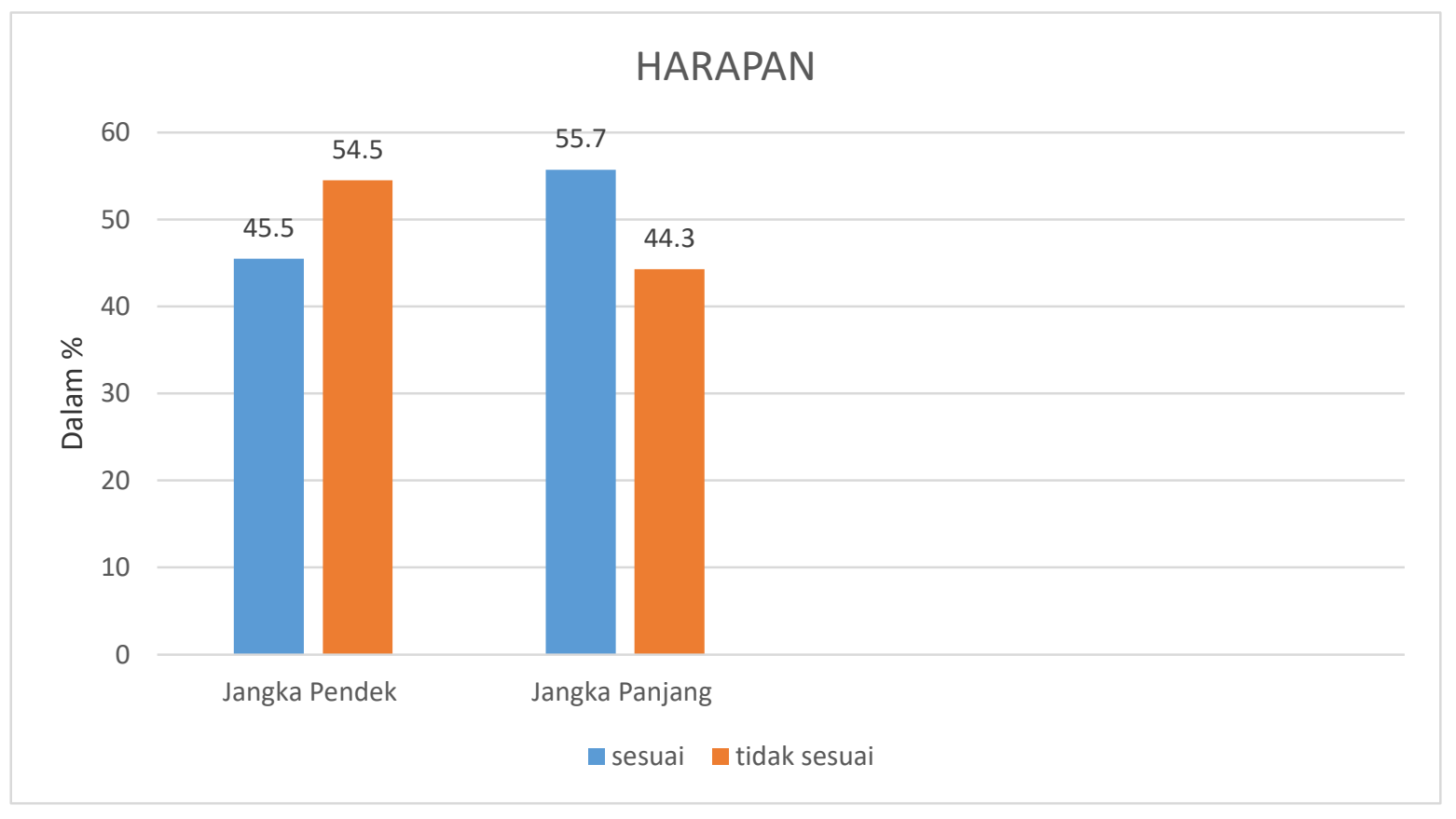

Gambar 5. Harapan jangka pendek dan jangka panjang mahasiswa

\section{KESIMPULAN}

Dapat disimpulkan untuk menjadi Entrepreneur bagi mahasiswa adalah

1. Bakat mahasiswa pria lebih tinggi dengan persentase $65,3 \%$ dibandingakn wanita $56,8 \%$

2. Menghasilkan banyak uang menjadi motivasi utama persentase $21,4 \%$,

3. Tidak ada modal merupakan hambatan utama persentase $55,8 \%$,

4. Bidang usaha yang dipilih ternyata tidak sesuai dengan pendidikan yang ditempuh Persentase $54,5 \%$.

5. Harapan jangka pendek tidak sesuai dengan pendidikan yang ditempuh, sedangkan pada jangka panjang sesuai dengan persentase $55,7 \%$

\section{Ucapan Terima Kasih}

Ucapan terima kasih kepada LPPM universitas pancasila atas bantuan dana penelitian Hibah Internal dengan skema pengabdian kepada Masyrakat 


\section{REFERENSI}

Jakarta, 21 Oktober 2021

Clleland, D.M. (2011). Characteristics of Successful Entrepreneurs. The Journal of Creative Behavior. Volume 21 pp 219-233.

Brück, T., Naudé, W. \& Verwimp, P. (2011). Small business, entrepreneurship and violent conflict in developing countries. Journal of Small Business and Entrepreneurship, 24(2) 161-78

Arafeh B., (2016). An entrepreneurial key competencies' model 2, Journal of Innovation and Entrepreneurship 5:26

Temidayo Gabriel Apata (2015). Entrepreneurship Processes and Small Farms Achievements: Empirical Analysis of Linkage. Journal of Entrepreneurship Management and Innovation (JEMI), Volume 11, Issue 2, pp: 105-127

Ahlem Omri dan Younes Boujelbene (2015), Entrepreneurial Team: How Human and Social Capital Influence Entrepreneurial Opportunity Identification and Mobilization of External Resources, Journal of Entrepreneurship Management and Innovation (JEMI), Volume 11, Issue $3,: 25-42$

David E.Rye (1996 ). Tool for Executives Wirausahwan The vest Pocket Entrepreneur penerbit PT. Prenhallindo .

Eva Kašperová, John Kitching, Robert Blackburn (2018). Identity as a causal power: Contextualizing entrepreneurs' concerns . The International Journal of Entrepreneurship and Innovation.

Anne-Flore Adam, Alain Fayolle (2016). Can implementation intention help to bridge the intention-behaviour gap in the entrepreneurial process? An experimental approach Th International Journal of Entrepreneurship and Innovation

Muhammad Shehryar Shahid Colin C Williams, Alvaro Martinez ( 2020). Beyond the formal/informal enterprise dualism: Explaining the level of (in)formality of entrepreneurs

The International Journal of Entrepreneurship and Innovation Identity as a causal power Contextualizing entrepreneurs' concerns

Thea van der Westhuizen, Marialauda Joel Goyayi. (2021) The influence of technology on entrepreneurial self-efficacy development for online business start-up in developing nations The International Journal of Entrepreneurship and Innovation

Petra Biberhofer, Claudia Lintner, Johanna Bernhardt 2018. Facilitating work performance of sustainability-driven entrepreneurs through higher education: The relevance of competencies, values, worldviews and opportunities. The International Journal of Entrepreneurship and Innovation 
Seminar Nasional Hasil Penelitian dan Pengabdian Kepada Masyarakat 2021

Pengembangan Ekonomi Bangsa Melalui Inovasi Digital Hasil Penelitian dan

Pengabdian Kepada Masyarakat

Jakarta, 21 Oktober 2021

(halaman kosong) 